\title{
The assessment of cost effectiveness and the effectiveness of cost assessment in cardiothoracic surgery
}

\author{
Vinay Badhwar, MD \\ From the Department of Cardiovascular and Thoracic Surgery, West Virginia University, Morgantown, WVa. \\ Disclosures: Author has nothing to disclose with regard to commercial support. \\ Received for publication April 15, 2018; accepted for publication April 16, 2018; available ahead of print May 12, \\ 2018. \\ Address for reprints: Vinay Badhwar, MD, Department of Cardiovascular and Thoracic Surgery, West Virginia \\ University, 1 Medical Center Dr, Morgantown, WV 26506-8059 (E-mail: vinay.badhwar@wvumedicine.org). \\ J Thorac Cardiovasc Surg 2018;156:608-9 \\ $0022-5223 / \$ 36.00$ \\ Copyright (c) 2018 by The American Association for Thoracic Surgery \\ https://doi.org/10.1016/j.jtcvs.2018.04.075
}

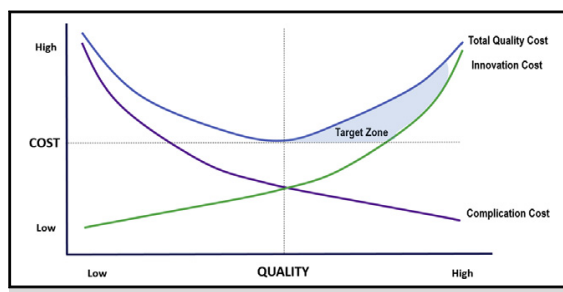

Optimizing cost and quality in cardiothoracic surgical innovation.

Central Message

Innovation is valued by its ability to reduce complications and enhance recovery and patient outcome.

See Article page 611. vascular Surgery, Hawkins and colleagues ${ }^{1}$ examined 86 mitral valve (MV) repairs and $16 \mathrm{MV}$ replacements performed via minimally invasive right thoracotomy. They compared these with 376 patients who received surgery performed via sternotomy to generate 74 propensity matched pairs for cost analysis. In this elegant study from the University of Virginia, minimally invasive surgeries conferred cost savings through reductions in ventilation time, transfusions, and ancillaries, despite increases in surgical time and surgical supplies. The authors ${ }^{1}$ determined that minimally invasive MV surgeries performed with peripheral perfusion were cost-neutral to sternotomy, matching observations from other recent institutional and multi-institutional experiences. $^{2-4}$

Cost, price, and value; how do we reconcile these elements when evaluating the effectiveness of innovation in thoracic surgery? Value is net patient contribution (quality + outcomes/cost) and cost-effectiveness attempts to balance the multitude of related factors when comparing alternate therapies. ${ }^{5-7}$ All thoracic surgeons are acutely aware of the effect their clinical activity might have on the fiscal health of their health system. All thoracic surgeons would also agree that innovation for innovation sake alone, not linked to quality maintenance or improvement, is not in the best interest of patients or health care. Currently, $14.5 \%$ of all MV surgeries are performed via minimally invasive or robotic methods and $11 \%$ of all MV repairs are performed robotically. ${ }^{8}$ Durable repair rates for degenerative MV disease and low surgical mortality and major morbidity rates must remain stable or improved as we innovate. As Hawkins et $\mathrm{al}^{1}$ and others ${ }^{2-4}$ have shown, adoption of minimally invasive approaches to MV repair or MV replacement is an example of innovation that can be performed with equal cost while maintaining and perhaps enhancing patient outcomes.

Targeting the optimal manner to improve costs while simultaneously enhancing quality can be challenging for many institutions. Innovation in the absence of quality improvement might lead to additional complications and cost. However, if the focus remains on improving patient quality and outcomes, innovation might be implemented in a coordinated effort using best practices and evidence. In thoracic surgery, the cost of complications and low quality are very high, but through quality improvement, reduction in complications lowers cost (Figure 1). Whereas the cost of innovation, such as minimally invasive and robotic technology, might be initially perceived as high, if its implementation is associated with simultaneous outcome improvement, one can achieve optimization of a program's total quality costs.

Estimating effectiveness and value of a given therapy must illustrate improvement in fatal and nonfatal events as well as quality of life or quality-adjusted life expectancy. ${ }^{5,6}$ Estimating actual costs is often difficult because of the interplay between actual and estimated direct and indirect hospital expense, case mix index, and charge capture according to diagnostic related group. Each of these elements might vary according to region and according to institutional methods of cost accounting. In the current study, Hawkins and colleagues ${ }^{1}$ used the Unified Billing 2004 estimation methodology. This used current International Classification of Disease versions 9 and 10 diagnosis and procedure codes applied to historical 2016 Centers for Medicare and Medicaid charges. This retrospective claims-based cost to charge ratio analysis provides a good estimate of institutional cost but this assumes that resource costs are proportional to charges. Another increasingly applied method of cost analysis is the time driven 


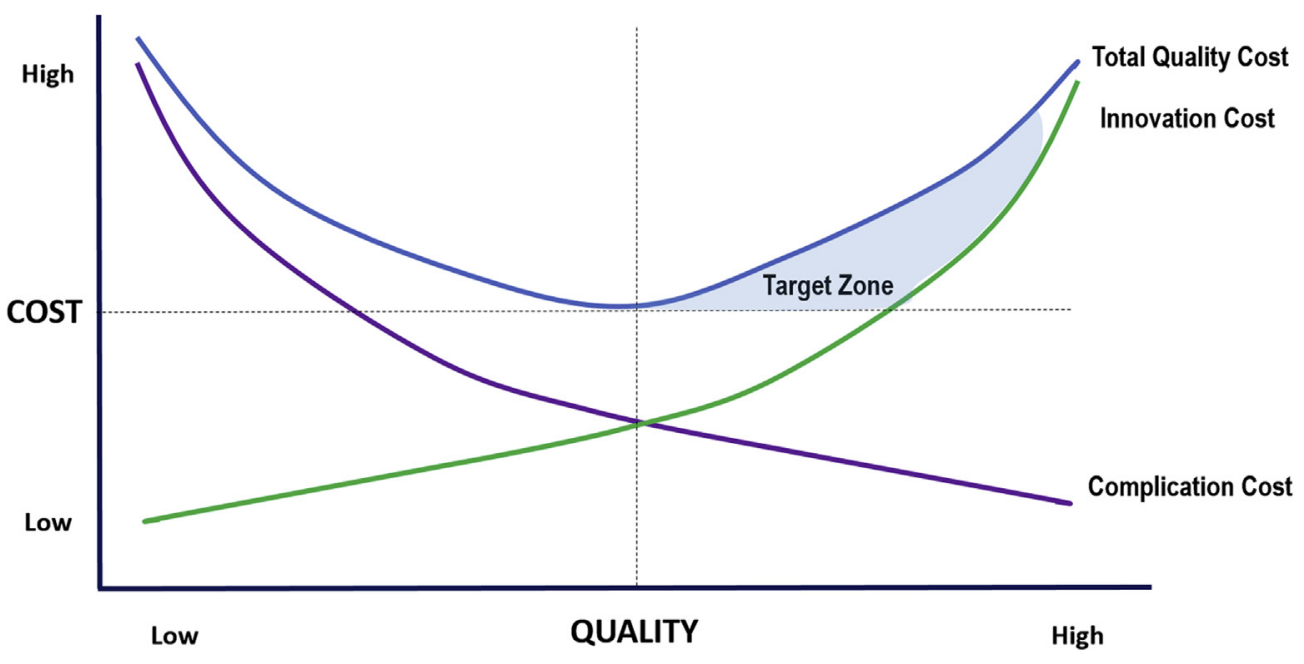

FIGURE 1. Optimizing cost and quality in cardiothoracic surgical innovation.

activity-based costing methodology. This manner of cost accounting addresses the inherent variability associated with cost to charge ratios by using a bottom-up costing methodology mapped directly to the actual patientspecific episode of care. This enables more precise accounting for the actual costs incurred by the specific patient encounter. When combined with direct and indirect costs by the episode and procedure, including physician fees and capital depreciation of equipment costs, one can create a holistic representation of actual costs incurred that are not on the basis of claims or charges. ${ }^{4,7}$ Using this activitybased costing method, a recent analysis of robotic MV surgery determined that robotic MV surgeries were costneutral to conventional MV surgeries in the primary episode of care, even when accounting for the capital cost of the robot. $^{4}$

Health care cost containment remains an ongoing focus of health systems, physician leaders, and payers who are now replacing fee-for-service with value-based payments for episodes of care. The expense of new technology might initially appear unpalatable but if it is accompanied by future value, it must be responsibly introduced to improve care. $^{6}$ The value of innovation should not be judged by cost alone but in the manner in which it is applied to reduce complications, enhance recovery, and patient outcome.

\section{References}

1. Hawkins RB, Mehaffey JH, Kessel SM, Dahl JJ, Kron IL, Kern JA, et al. Minimally invasive mitral valve surgery associated with excellent resource utilization, cost, and outcomes. J Thorac Cardiovasc Surg. 2018;156:611-6.

2. Atluri P, Stetson RL, Hung G, Gaffey AC, Szeto WY, Acker MA, et al. Minimally invasive mitral valve surgery is associated with equivalent cost and shorter hospital stay when compared with traditional sternotomy. J Thorac Cardiovasc Surg. 2016; 151:385-8.

3. Downs EA, Johnston LE, LaPar DJ, Ghanta RK, Kron IL, Speir AM, et al. Minimally invasive mitral valve surgery provides excellent outcomes without increased cost: a multi-institutional analysis. Ann Thorac Surg. 2016;102:14-21.

4. Coyan G, Wei LM, Althouse A, Roberts HG, Schauble D, Murashita T, et al. Robotic mitral valve operations by experienced surgeons are cost-neutral and durable at 1-year. J Thorac Cardiovasc Surg. 2018 [In press].

5. Ferket BS, Oxman JM, Iribarne A, Gelijns AC, Moskowitz AJ. Cost-effectiveness analysis in cardiac surgery: a review of its concepts and methodologies. J Thorac Cardiovasc Surg. 2018;155:1671-81.e11.

6. Moreno SG, Ray JA. The value of innovation under value-based pricing. J Mark Access Health Policy. 2016;4:1-9.

7. Ken Lee KH, Matthew Austin J, Pronovost PJ. Developing a measure of value in health care. Value Health. 2016;19:323-5.

8. Badhwar V, Rankin J, He X, Jacobs J, Gammie J, Furnary A, et al. The Society of Thoracic Surgeons mitral repair/replacement composite score: a report of The Society of Thoracic Surgeons quality measurement task force. Ann Thorac Surg. 2016;101:2265-71. 